\title{
Preferences of Young Stroke Survivors to Meet Their Unique Needs It Is Time to Listen
}

Christa O'Hana S. Nobleza, MD, MSCI

Neurology ${ }^{\circledR}$ 2021;96:ee1809-e1811. doi:10.1212/WNL.0000000000011665

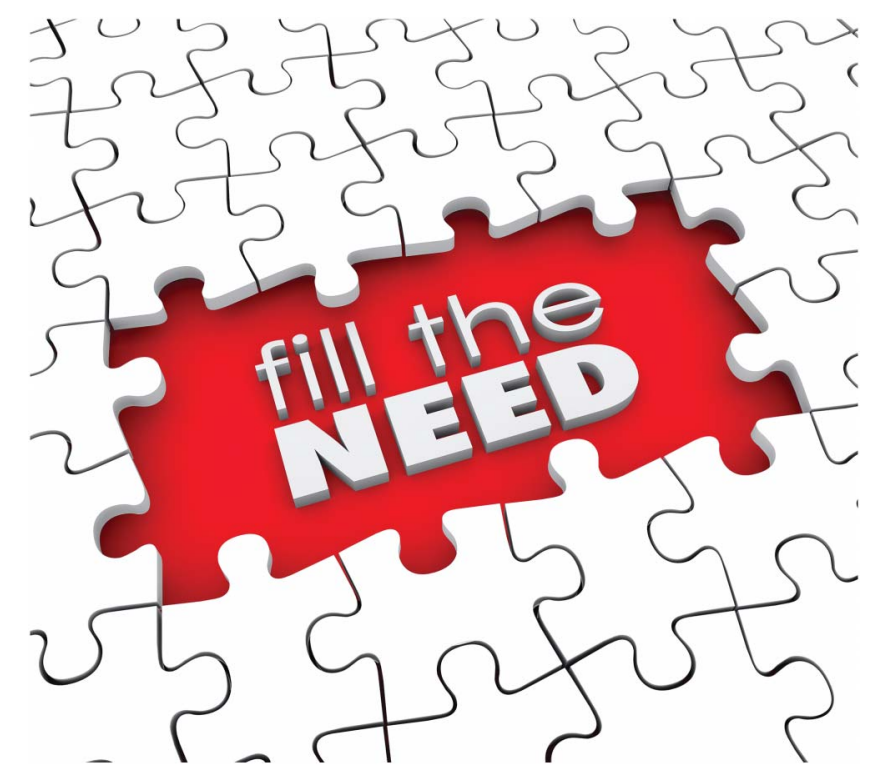

Stroke is usually thought of as a disease that affects only older patients. However, more recently, there is increasing awareness that stroke also happens in younger adults. Yet, younger patients may have different needs than older stroke survivors. Some of the reported unmet needs of younger patients include information, transportation, home help, personal care, and therapy. ${ }^{1}$ Many researchers have suggested ways to best meet these needs. These methods include developing personalized plans for helping patients adapt at home, and proactively reaching out to patients rather than waiting for them to call their health care provider.

\section{What Did the Authors Study?}

In a study featured in this issue of Neurology ${ }^{\circledR}$, Keating et al. ${ }^{2}$ sought answers to the following questions:

1. What do young patients with stroke need as compared to older patients?

2. How do they prefer to have these needs met?

Stroke in young adults is relatively rare but has increased by about $40 \%$ in the past 2 decades. $^{3}$ The lifetime cost of stroke is high. For men aged 45 and 55 years, the cost is estimated to be about $\$ 183,000$ USD (200.7 million KRW), and about $\$ 75,000$ USD (81.9 million KRW), respectively. ${ }^{4}$ Stroke affects not only the individual, but also their families, friends, employers, and community. These effects have yet to be fully studied. However, working closely with patients during recovery and helping them reconnect with their community should be top priority in stroke care for young survivors.

\section{How Was the Study Done?}

This study included stroke survivors from 18 to 55 years of age. It asked them to participate in an online survey during their recovery period. This survey collected information about
Related Article

Young Stroke

Survivors'

Preferred Methods

of Meeting Their

Unique Needs:

Shaping Better

Care

10.1212/WNL.0000000000011647 
Table Findings and Potential Applications

\begin{tabular}{ll}
\hline Findings & Implications \\
\hline $\begin{array}{l}\text { People who lived with a carer or high level of distress will likely } \\
\text { have unmet needs. }\end{array}$ & Consider closer or more frequent outreach or follow-up for needs assessment. \\
\hline $\begin{array}{l}\text { Worse disability is associated with unmet needs socially, in } \\
\text { relationships, and in daily life. }\end{array}$ & $\begin{array}{l}\text { Consider focusing on ways to address social needs and activities of daily living earlier in } \\
\text { the course of stroke care (e.g., home modification setup while still in the hospital). }\end{array}$ \\
$\begin{array}{l}\text { Women were more likely to have unmet needs socially and in } \\
\text { relationships than men. }\end{array}$ & $\begin{array}{l}\text { Recommend closer and more frequent follow-ups for women with a focus on social and } \\
\text { relationship needs. }\end{array}$
\end{tabular}

Women, urban-dwelling patients, and patients with high level of Recommend timely appointment with live interaction with a health care professional disability almost always preferred live interaction with a health with close follow-up regarding feedback about the visit.

care professional.

Patients 35 and younger showed no preference for seeing a health

care professional.

Consider early needs assessment and evaluation of follow-up options other than faceto-face interaction before leaving the hospital.

Patients with worse disability or distress level usually prefer interaction with a live professional.

Consider timely appointment with live interaction with a health care professional not only for follow-up but also for rehabilitation and neuropsychology if needed.

A list of tips was preferred by respondents who were male, had a carer, had low distress level, or lived in regional Australia

Consider various tips sheets for different categories of need to be readily available in all phases of stroke care.

Young stroke survivors are receptive to several methods besides traditional face-to-face meeting with a professional.

Consider early evaluation of logistics of other methods to be able to make them available in a timely manner for patients with stroke, especially young stroke survivors.

the patients, their needs, and their preferred methods of meeting those needs. The survey tool was developed in partnership with consultants from the young stroke community. This helped ensure that the survey was personalized for young patients with stroke.

The researchers divided the types of needs into 6 major areas:

1. Body and mind (movement, swallowing, pain, health and well-being)

2. Emotions (identity, moodiness, anger, anxiety)

3. Information (care services, stroke type and cause)

4. Daily life (household duties, community tasks, employment, school)

5. Relationships (strain on close relationships, raising children, sexual health)

6. Social (isolation, lack of understanding from family and friends, missing "normal activities")

\section{What Did the Study Show?}

A total of 171 young stroke survivors from 5 continents participated in the survey. Only 5 respondents reported no needs at all. Most participants described at least one need in each category. The most common needs were in the body and mind category. The information category was the least mentioned. Based on this information, one might determine that recovery efforts for young stroke survivors should focus on helping them adjust to the physical and psychological effects of stroke. In addition, the researchers found that young stroke survivors preferred to address these types of needs by using a list of tips and by talking face-to-face with a health care professional. Other options of meeting these needs included fact sheets with graphics, podcasts or other media resources produced by young stroke survivors or researchers, articles about young stroke survivors' experiences, access to peer support, or telephone conversations with a trained helper. Interestingly, telehealth consultation was the least favored. This is an important finding because recently, in some countries like the United States, follow-up visits for stroke survivors have shifted mostly to telehealth. The researchers' other major findings are listed in the table. They also found that a higher level of distress was associated with unmet needs. Some problems were connected to specific categories of unmet needs, such as worse disability leading to unmet needs in social relationships and daily life.

\section{Why Do These Findings Matter?}

Stroke is more than just a medical condition. Unmet needs after stroke affect many aspects of a stroke survivor's lifeemotional, psychological, physical, financial, social, and more. Addressing all these aspects is important for recovery. Systems of care should align processes and programs that address these specific needs. They should also strive to use the patients' preferred methods for meeting these needs. For example, a 23-year-old stroke survivor may prefer a list of tips to follow for coping and adapting in their daily life, rather than seeing a health care professional. A severely disabled patient with stroke may prefer to interact with a live professional. It is important to rethink how the effectiveness of these methods is measured. It is also key to measure the psychological, social, and emotional effects on young stroke survivors in addition to the physical aspects of their recovery. The study by Keating et al. ${ }^{2}$ took a new approach by exploring the different ways to address young stroke survivors' specific needs. Having unmet needs may affect the overall health outcomes of young stroke survivors in the long run. Through this study, we can see that there are certain methods young stroke survivors prefer for meeting these needs. The patients should not be alone in their recovery, and we should listen to what they are asking for when it comes to their needs. 


\section{About Stroke in the Young}

Stroke in the young generally refers to stroke that occurs in patients who are 18-64 years old. This age group represents $10 \%-15 \%$ of all strokes in the United States. ${ }^{3}$ The most common type of stroke is a clotting stroke (ischemic stroke).

\section{What Causes an Ischemic Stroke?}

Common causes include the blockage of small or large blood vessels, a clot that travels from the heart to the brain, irregular heart rhythm, an abnormal blood vessel tear, abnormal blood vessel inflammation, and others.

\section{What Do We Know About Stroke?}

Most studies report that stroke is more common among men, but women are more likely to become more disabled from stroke and have a higher death rate. ${ }^{5}$ Strokes are more common in Black and Hispanic adults across all age groups, as compared to White adults. ${ }^{6}$ People with the traditional stroke risk factors of high blood pressure, high cholesterol, diabetes, and smoking are at greater risk for stroke as well. ${ }^{3}$

\section{What Are Some of the Signs of Stroke?}

Common symptoms of stroke include sudden weakness on one side of the face or body, numbness, slurred speech, and the inability to get words out. One may also have sudden dizziness, double vision, difficulty walking, nausea, and vomiting.

\section{How Is Stroke Treated?}

If identified early, strokes are treated with so-called "clot busters." These are medications given to a patient with stroke to break up the clot that is causing the stroke. This returns blood flow to the brain. More recently, it has become possible to sometimes remove the clot that caused the stroke. This process is called mechanical thrombectomy.

\section{How Can Stroke Be Prevented?}

Initial steps to prevent stroke focus on risk factors that can be controlled. These include controlling blood pressure, preventing or quitting smoking, controlling blood sugar, and getting regular exercise. ${ }^{3}$ Taking medications for cholesterol and daily aspirin can also help. ${ }^{3}$

\section{For more information:}

\section{Brain \& Life}

brainandlife.org

\section{American Stroke Association stroke.org/}

\section{Neurocritical Care Society}

neurocriticalcare.org/resources/family-patientresources

\section{References}

1. Chen T, Zhang B, Deng Y, Fan JC, Zhang L, Song F. Longterm unmet needs after stroke: systematic review of evidence from survey studies. BMJ Open 2019;9:e028137.

2. Keating J, Borschmann K, Johns H, Churilov L, Bernhardt J. Young stroke survivors' preferred methods of meeting their unique needs: shaping better care. Neurology 2021; 96:e1701-e1710.

3. Yahya T, Hashim Jilani M, Khan SU, et al. Stroke in young adults: current trends, opportunities for prevention and pathways forward. Am J Prev Cardiol 2020;3.

4. Kang HY, Lim SJ, Suh HS, Liew D. Estimating the lifetime economic burden of stroke according to the age of onset in South Korea: a cost of illness study. BMC Public Health 2011;11:646.

5. Madsen TE, Khoury JC, Leppert M, et al. Temporal trends in stroke incidence over time by sex and age in GCNKSS. Stroke 2020;51:1070-1076.

6. Gardener H, Sacco RL, Rundek T, Battistella V, Cheung YK, Elkind MS. Race and ethnic disparities in stroke incidence in the Northern Manhattan Study. Stroke 2020;51:1064-1069. 


\title{
Neurology
}

\author{
Preferences of Young Stroke Survivors to Meet Their Unique Needs: It Is Time to \\ Listen \\ Christa O'Hana S. Nobleza \\ Neurology 2021;96; $1809-\mathrm{e} 1811$ \\ DOI 10.1212/WNL.0000000000011665
}

This information is current as of March 29, 2021

\section{Updated Information \&} Services

References

Permissions \& Licensing

Reprints including high resolution figures, can be found at: http://n.neurology.org/content/96/13/e1809.full

This article cites 5 articles, 2 of which you can access for free at: http://n.neurology.org/content/96/13/e1809.full\#ref-list-1

Information about reproducing this article in parts (figures,tables) or in its entirety can be found online at:

http://www.neurology.org/about/about_the_journal\#permissions

Information about ordering reprints can be found online: http://n.neurology.org/subscribers/advertise

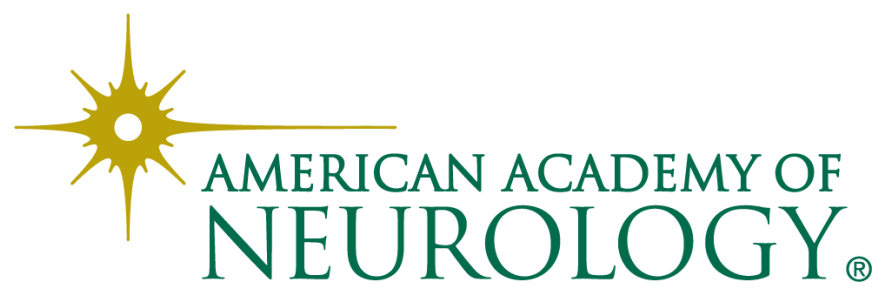

